\title{
$\mathrm{DJ} \mathrm{M}$ \\ Volume 7 - Fall 2011 \\ djim.management.dal.ca
}

\section{Success Through Collaboration: What the Players of World of Warcraft Can Teach Us About Knowledge Production and Sharing in Virtual Communities}

\section{Tammy Ann Whynot}

\begin{abstract}
As of October 1, 2010, 12 million subscribers around the world play massive multiplayer online role-playing game World of Warcraft (WoW). Outside of the formal framework of the game, players have established a flourishing network for the creation and sharing of knowledge. Motivations for playing the game may appear obvious-as a game, it is a form of recreation or entertainment-but why do players step outside the game world to participate in the creation and sharing of knowledge? Theories of social capital, social exchange, and social orientation offer insight and explanation. Using the WoW community as a case study, this paper illustrates how virtual communities produce and exchange knowledge through strong, voluntary, social bonds. It is also demonstrated that as a result of these activities, broader goals are met and success is achieved.
\end{abstract}

About the Author(s): Tammy Whynot is an MLIS candidate at Dalhousie University, in her first year of study. She is a graduate of Dalhousie University with a BA in Political Science and Comparative Religion, and St. Mary's University with a BA in Asian Studies. She is an avid reader, gamer, and participant in online social networks, with an interest in how these activities intersect to result in the sharing of information and creation of knowledge. She currently resides in Halifax with her cat, She-Ra.. 


\section{Introduction}

Virtual communities are systems of informal learning in which strong social bonds foster the creation and sharing of knowledge (Chu, 2009). The players of World of Warcraft (WoW), a massively multiplayer online role-playing game (MMORPG), form an online communities that have understood that collaboration is essential to success. To this end, players have ventured far outside the formal framework of the game world to form online networks where they create and share the knowledge required to achieve both personal and collaborative goals. This paper will discuss how the voluntary social ties amongst the player base of the game facilitate the production and exchange of knowledge, aiding them in attaining a wider understanding of the role of online social networks in the synthesis of information and dissemination of knowledge. The discussion will begin with an introduction of virtual communities and the WoW community in particular. Information, knowledge, and knowledge production will be defined, followed by an exploration of the reasons why people choose to share knowledge, referring to theories of social capital, social exchange, and social orientation. Throughout this discussion, it will be demonstrated that using communication tools available on the Internet, virtual communities are fertile grounds for the production and sharing of both tacit and explicit knowledge.

\section{Places of Informal Learning}

Chiu, Hsu, and Wang (2006) defined virtual communities as "online social networks in which people with common interests, goals, or practices interact to share information and knowledge, and engage in social interactions" (p. 1873). These communities are commonly places of informal learning where the social aspect of engaging in activities and discussions is an expediter of knowledge sharing, rather than a barrier or distraction (Chu, 2009). Chiu et al. (2006) further argue that "without rich knowledge, virtual communities are of limited value" ( $p$. 1873). These communities may take divergent forms; for example, they may be created by a business, an academic institution, or by the fans of a particular genre of entertainment. Networks formed by companies to foster the exchange of knowledge between employees, known as virtual communities of practice (VCoPs), have been the focus of much research; they are of keen interest to corporations in formulating knowledge management strategies (Ardichvili, 2008). These communities encourage employees to voluntarily share their experiences and insights without requiring face-to-face contact; something which may save the organization expense and ensure the expertise of experienced workers is passed on (Ardichvili, 2008).

The virtual community we will be discussing may be broadly defined as encompassing the players of a massively multiplayer online role-playing game (MMORPG), a sub-genre of the massively multiplayer online game (MMOG) (Putzke, Fischbach, Schoder, \& Gloor, 2010). 
MMOGs are games that are played over the Internet simultaneously by hundreds, thousands, or even millions of people, interacting with the game world and fellow players to advance an overarching narrative. The structure of the games provide a framework for social interaction to take place; according to anthropological research by Chen (2008), "players start with the base game but need to develop myriad social norms, etiquette, and practices that ultimately help define what it means to be a player of a particular game" (p. 50). Many of the MMOGs currently available require the user to pay a monthly fee for access, creating a booming market for entertainment by subscription (Shivel, 2010).

\section{World of Warcraft}

Launched on November 23, 2004, World of Warcraft (WoW), published by Blizzard Entertainment, is the world's most-played subscription MMORPG, having reached 12 million user accounts by October, 2010 (Blizzard Entertainment, 2010a). The virtual world that exists within the game, Azeroth, is rendered in rich, three dimensional environments, with climates ranging from tropics to tundra. Within this world, the sun rises and sets; it rains, snows, and rages firestorms. Players begin with a level 1 character belonging to one of 10 different races, and one of 12 classes, allowing for customizable gameplay within the high-fantasy setting. For example, a player may choose to play as a mage who wields magical spells or as a rogue who prefers to lurk in shadows and master poisons (Withers, 2010). Advancement of a character from level 1 to level 85 occurs through the completion of objectives, known as quests, and through the defeat of enemies, the most powerful of which are known as bosses. As the character advances, he/she gains in-game skills and items, while progressing a narrative; all of which add realism to the gameplay experience (Chen, 2008).

WoW is housed on multiple servers located around the world, with individual copies of the game being installed on the personal computers of every player (Golub, 2010). The game world develops through a "co-evolutionary process" (Golub, 2010, p. 27) where developers at Blizzard design content, while players explore and test that content. The game is then tweaked by the developers through downloadable upgrades known as patches (Golub, 2010). It has also been part of Blizzard's strategy to keep players engaged by releasing periodical expansions to the existing game, as there is some danger of the game experience growing stagnant. As Shivel (2010) writes, "the same things happen over and over again in World of Warcraft. A quest may be new to you, but many others have done it before and will do it after you" (Shivel, 2010, p. 211). This repetition is experienced by individuals who choose to create multiple characters, as each one is required to complete the same quests to advance in level. On December 7, 2010, the most recent expansion, Cataclysm, overhauled the existing game world in the form of a global catastrophe that shattered Azeroth, destroying towns, eliminating natural resources, and bringing competing factions within the game to the brink of war (Withers, 2010). As part of this change, the overall story of the world has been adjusted, with 
new opportunities to advance narrative as the players attempt to recover from the crisis and strengthen their characters to fight new enemies (Withers, 2010).

\section{Cooperation, Knowledge, and In-Game Success.}

As will be discussed below, success in WoW may be measured differently according to the desired outcomes of the player. Despite the differing goals players may have, learning is the key to achieving those goals. For some players, success may be attained through acquiring rare items for their character; for others, it may be in continuing to discover the game's story through completing quests or cooperating with peers to defeat a difficult boss. Still others may be content to pursue in-game professions or seek to accomplish a specific task called an achievement ("Achievement," 2010). For many, ultimate success is determined by how far a player, or an association of players known as a guild, has advanced through the most challenging boss encounters, available to characters who have reached the maximum level-a process known as progressing through end-game content (Golub, 2010). To meet any of these goals, knowledge is required to navigate the vastness of the game world.

MMORPG gameplay requires simultaneous attention to skill development...to play well requires intense attention to player statistics, both teamwork and leadership skills, and knowledge of how best to use the subtleties of a particular class of character. (Shivel, 2010, p. 206)

Mastering an in-game profession or finding a rare item as an individual may be conducted through trial and error, but it is also achievable if one has a reliable reference to consult. To progress as a guild to end-game content requires each person to understand how to best play his/her role within the group, necessitating a clear understanding of how every other class in the game operates. One must also learn about the specifics of the content that is being attempted, as the encounters at end-game are, as described by Golub (2010), "technically challenging, phenomenologically intense, emotionally compelling, and deeply connected with self-esteem and group membership" (p. 32). As such, it is an accepted social practice that each player will prepare in advance of attempting this content by engaging in previous study (Chen, 2008). Learning about the encounter and what is expected of each individual is a responsibility that players trust each other to undertake (Chen, 2008).

This learning is part of a wider process of synthesizing information, generating knowledge, and sharing the knowledge one possesses. In order to understand this process, it is first important to make clear the distinction between information and knowledge and to recognize the relationship between the two. Numerous definitions of information are available in Information Science literature. Edwin Parker (1974) defined information as "the pattern of organization of matter and energy" (as cited in Bates, 2005, para. 16). Working with this definition, information 
is something that simply exists; it is separate from context, meaning, or understanding. It is through the synthesizing of information by a person that knowledge emerges: knowledge is information given meaning (Bates, 2005; Raban \& Rafaeli, 2007).

Knowledge can be conceptualized in greater depth as belonging to one of two types identified by Nonaka and Takeuchi (1995): tacit and explicit (as cited in Cyr \& Choo, 2010). Tacit knowledge is intangible, informal, and based upon a person's experiences, emotions, or values. This category of knowledge encompasses that which may be challenging to pass on to another individual, including "subjective insights, intuitions, and hunches" (Cyr \& Choo, 2010, p. 286). While several sources assert that tacit knowledge is of particular value to organizations as it is a resource that is difficult to acquire (Yang \& Farn, 2009), Cyr and Choo argue that there is a lack of empirical work to support this assumption. Choo (1998) further defines tacit knowledge as it relates to a group as the "distinct practices and relationships that emerge from working together over time-the social fabric that connects communities" ( $p$. 117).

Explicit knowledge is knowledge that can be "formally and systematically stored, articulated, and disseminated in certain codified forms" (Yang \& Farn, 2009, p. 211). In Choo (1998), a knowledge production process identified by Nonaka and Takeuchi (1995) demonstrates how tacit knowledge may be transformed into explicit; a process which will be discussed further below. The two types of knowledge are also distinguished by how they may be shared: while the sharing of tacit information is facilitated by social interaction or informal systems, sharing explicit knowledge can be aided through information technology or formal systems (Yang \& Farn, 2009).

\section{Knowledge Production Frameworks}

Knowledge production is described by Nonaka and Takeuchi (1995) as occurring in five phases: "(1) sharing tacit knowledge, (2) creating concepts, (3) justifying concepts, (4) building an archetype, and (5) cross-levelling knowledge" (Choo, 1998, 127). As Choo explains, in this creation process skills and experiences are shared when working toward a common goal. This knowledge is then turned into explicit concepts through communication, after which the concepts are evaluated to determine if they meet the needs of the community. A concrete or tangible model is then formed, wherein the tacit is made explicit. Finally, this new explicit knowledge is used to prompt the creation of new cycles of knowledge (Choo, 1998).

Choo's (1998) explanation of Nonaka and Takeuchi's model is applicable to our discussion of virtual communities; however, it is grounded in face-to-face interaction between members of a professional organization. To understand how knowledge is shared amongst members of an online community that may be formed for non-professional purposes, it is useful to examine 
the framework presented by Hersberger, Murray, and Rioux (2007). They posit that information sharing can be understood in terms of a four-tired pyramid. In this pyramid, the bottom layer is membership, comprised of the efforts an individual invests in the community. Second is the role of online social networks as information networks. The third tier is the exchange of information, where information seeking and needs contribute to the evolution of relationships in an online community. The final tier at the top of this pyramid is information sharing (Hersberger et al., 2007). It is worth noting that while this framework is designed to analyze the exchange of information, the top tier of their pyramid describes a process of synthesizing, understanding, and dissemination that meets our previous definition of knowledge. Within both of these frameworks, we can see that it is the social ties between members that are the driving force of knowledge production and sharing.

A review of the official website for World of Warcraft demonstrates that Blizzard Entertainment is well aware of the value in the social relationships between players. It has created several channels through which players may exchange knowledge, including in-game communication tools and web forums (Blizzard Entertainment, 2010b). However, as these methods are moderated by Blizzard staff, they exist as part of the official framework of the game and will be excluded for the purposes of our discussion; rather, we will focus on the way gamers have, as argued by Golub (2010), "taken this basic structure and added to it to create a full-fledged institution which has outlasted the individuals who started it to create an enduring cultural system" (Golub, 2010, p. 28).

\section{Member-generated content}

Amongst the players of WoW, as in any virtual community, content generated by members is highly significant (Chiu et al., 2006). The social networks available online for players reach well beyond those offered by Blizzard, with fan- and player-created websites forming an "online collective for guidance" (Shivel, 2010, p. 208). Players look to other players as the most common source for information about where to find an object or item, what to do next in game, or how to best play their character's class (Shivel, 2010). This is accomplished by using the full range of communication tools available on the Internet: both information and knowledge are exchanged through forums, chat rooms, wikis, podcasts, streaming video, and blogs; with Chen (2008) arguing that the most common tool is the forum. While acknowledging that knowledge is contributed by players through a plethora of social networks, we will limit our discussion to three websites popular in the WoW community: the online encyclopaedia, Wowwiki (2010); a web forum, Elitist Jerks (2010); and the searchable database, Wowhead (2010).

Wowwiki (2010), a portmanteau of the terms WoW and wiki, was launched one day after the official release of the game and currently contains 87,813 content pages related to the 
Warcraft universe. ("Statistics," 2010; "Wowwiki:About," 2010). A wiki is a collection of articles collaboratively authored and easily accessible for editing by anyone, allowing for the continual addition of new topics and rapid updating of existing entries (Fitch, 2007). Fitch (2007) writes that wikis are of value to an organization as repositories of both tacit and explicit knowledge. In terms of explicit knowledge, he writes that a wiki would be an "ideal location to house an agency's policies and procedures manual" (Fitch, 2007, p. 82). As for tacit knowledge, Fitch argues that a wiki can aid a business in coping with staff turnover as experts retire, taking with them their understanding of how things work in actuality within the company. In this way, the wiki may be a place of "organizational remembering" (Fitch, 2007, p. 82). In the context of WoW, Fitch's main points still apply. In the case of explicit knowledge, Wowwiki provides articles on Blizzard's official policies, game lore, and MMOG community practices. For example, the article "Dragon Kill Points" (2010) explains a loot distribution system that is commonly used by MMORPG players from various games. Tacit knowledge, the sum of experience gained by individuals, may be lost as players quit the game, impacting the WoW community in a similar fashion as the retirement of employees from a company. In this way, Wowwiki serves to catalogue a valuable and sometimes difficult to retain resource-the knowledge gained firsthand through experiencing gameplay.

Web forums are, according to Kollock and Smith (1996), one of the key components needed for "creating a sustainable online community" (as cited in Chen, 2008, p. 70). They allow for community members to engage in discussions and provide interactive assistance to one another, responding to questions and serving as repositories of information and knowledge (Chu, 2009). Elitist Jerks (2010) is a forum created by a top-ranked guild devoted to the discussion of WoW game mechanics and effective strategies for advancing through end-game content (Elitist Jerks, 2010a). What differentiates this web forum from numerous others in the WoW community is the emphasis on well thought-out, articulate, and useful contributions to the knowledge of the player base. In the posted forum rules, users are given a frank induction into what Raban and Rafaeli (2007) call the "sharing norms" (pg. 2369) of the website:

Whining in any form is forbidden...Do not post unless you have something new and worthwhile to say. Do not bump, quote for truth, cross-post, or post only to say thanks. We don't want to hear your funny story about something that happened in your raid last night, your baseless speculation is unproductive, and your idea for a new ability really isn't that interesting. If you have an idea you'd like to share with the community, support it with analysis, testing, or both that indicates you've put some thought into it...Do not beg for hand-holding. These are forums for discussion and analysis, not for answering any question that you might happen to dream up (Elitist Jerks, 2010a).

With this somewhat harsh and condescending tone directed at community members by the administrators of the forum, one may wonder why someone would choose to participate at all. 
The answer lies in the high bar Elitist Jerks sets for quality and the reputation of the creators of the website as experts. As Putzke et al. (2010) write, players who have a high performance in the game are perceived as having a higher expertise, placing them in an advantageous position in the hierarchy of the community and increasing the likelihood that they will be sought after as purveyors of knowledge. The approach of Elitist Jerks is well-appreciated by the WoW community: at the time of writing, the forum had 372,465 registered members with $1,807,477$ individual posts contained in 109,915 threads (Elitist Jerks, 2010b).

Wowhead (2010) is, according to its player-creators, "our contribution to this wonderful game" (Wowhead, 2010, para. 1). It is a searchable database containing data about items, personalities, places, and events in the game world, uploaded by individual players automatically through a downloadable client (Wowhead, 2010). Knowledge is created and shared by community members who interpret this data on the website by offering commentary and engaging in discussion about specific database entries. For example, players who are searching for an item not only receive information about the particular object but are provided with insight or advice from other players, as well as a space to "ask questions, discuss important WoW-related topics, recommend and share favourite add-ons, and much more!" (Wowhead, 2010, para. 2).

The client used by Wowhead (2010) to gather data from individual players is a type of add-on. Add-ons are "specialized technical measures that are undertaken to develop knowledge about the game" (Golub, 2010, p. 33). These are programs written by members of the community using a Blizzard-published application program interface, usually for the purposes of enhancing gameplay experience through taking raw data from the game state and transforming it into useful knowledge (Golub, 2010). The Wowhead client is an add-on that takes data from the game and transmits it to an online database; other examples of add-ons are programs that modify the interface of the game, providing feedback on a player's individual performance or offering guidance in defeating a boss (Golub, 2010). According to Chen (2008) "many players supplement WoWs built-in interface with user-created add-ons, which replace or augment certain design elements to help them keep track of all the information in the world" (p. 58). Serious players who are attempting end-game content and progression will rely heavily on add-ons to cope with the cognitive load required for boss encounters, sacrificing the visual realism of the game world for instant information and knowledge (Chen, 2008).

Through all of these networks, a crucial aspect to sharing and generating knowledge is using a shared language. Chiu et al. (2006) write that a common vocabulary, including subtleties and assumptions, forms a type of shared code that fosters the understanding of goals and defines expectations of proper behaviour in the community. The language of the WoW community can be confusing to an outsider: not only are there the many terms already introduced in the discussion above, but players' speech is peppered with acronyms, shorthand, and phrases 
common to Internet culture. Wowwiki (2010) contains entries on how to access this vocabulary, providing a comprehensive list of terminology, acronyms, and misspellings ("World of Warcraft Terminology," 2010).

\section{Motivations for Players to Generate Content}

The willingness to contribute to the supply of knowledge is critical to the survival of online communities, something which may prove to be a challenge, as knowledge sharing is a volitional process (Chiu et al., 2006; Cyr \& Choo, 2010). Chen (2008) and Raban and Rafaeli (2007) draw upon studies of sharing behaviours in online communities to assert that, though people devote significant time to gathering information and synthesizing that information into knowledge, they often demonstrate a willingness to share it without any response or recompense. This apparent selflessness prompts the question, as posed by Ardichvili (2008): if "knowledge is power, why share it?" (p. 543). Literature on the sharing of knowledge within virtual communities proposes differing theories as to the motivation behind sharing behaviour. Ardichvili argues that sharing is based upon "personal benefit, community-related expectations, and normative beliefs" (p. 549), a statement supported by Chiu et al. (2006) who identify desirable outcomes to knowledge sharing as being both "community-related and personal" (p. 1873). To understand why the players of WoW share knowledge, we will look at both community and personal benefits, incorporating the concepts of social exchange theory, social capital, and social value orientation.

As noted above, based on the collaborative nature of MMORPGs, a strong community is required to succeed in WoW. Those who approach knowledge sharing with a community focus in mind may view their contributions as part of a greater social obligation. For example, in researching virtual communities of practice (VCoPs) Ardichvili (2008) found that study participants saw their knowledge as a public good and therefore belonging to the entire organization (p. 544). This sense of a public good would counter instincts one may have to hoard knowledge. Community outcomes of sharing may include helping others to increase their enjoyment and understanding of the game, or the progression of a group in the game's narrative and content. These outcomes are supported in the research of Wasko and Faraj (2000), who conducted a study in the motivations behind individuals' knowledge sharing behaviours in online communities. They found that the "largest category of participants shared their knowledge because they enjoyed sharing their experiences, acted with altruism, and wanted to contribute to the betterment of community knowledge (31.3 percent)" (as cited in Cyr \& Choo, 2010, p. 829).

The sharing of knowledge in a community may also be viewed through the lens of social exchange theory, which sees knowledge sharing "as an exchange of a valuable resource between two parties which is expected to incur costs borne by the knowledge owner and 
bestow benefits to the recipient" (Cyr \& Choo, 2010, p. 826). To those who are communityfocused, the benefits to the community outweigh the personal costs associated with imparting knowledge. The exchange may also be seen by the contributor as equitable, as they intend to receive knowledge from the community in turn, in a process of mutual reciprocity (Chiu et al., 2006; Cyr \& Choo, 2010).

Social capital theory also offers some insight into the community focus of knowledge sharing. This theory advances the idea that factors such as "social interaction ties, trust, norm of reciprocity, identification, shared language, and shared vision...lead to greater level of knowledge sharing in terms of quantity or quality" (Chiu et al., 2006, p. 1884). Communityoriented players will therefore share knowledge with the community for the main purpose of participating in the community itself because the community is something they value. The particular value one assigns to the community and its role in facilitating the sharing of knowledge is explained in the players' social value orientation. This concept explains that those who are, by nature, cooperative or prosocial are inclined to aid those who are interdependent without maximizing their own personal outcomes (Cyr \& Choo, 2010).

To those with an individualistic social orientation, the personal benefits of sharing knowledge are the desired outcomes. The literature emphasizes the impact of knowledge sharing on one's standing within the community. Cyr and Choo (2010) cite the benefits of respect from others, while Raban and Rafaeli (2007) identify gratitude and a heightened reputation as key benefits. Ardichvili (2008) writes that the sharing of information is undertaken by those who seek to establish themselves as experts. In the WoW community, like in professional communities, the value of prestige should not be underestimated. As seen in the example above, the web forum Elitist Jerks (2010) has achieved popularity based on its commitment to the sharing of quality knowledge. It is also plain from the posted forum rules that there is a community-based derision of posts to the forum which are seen as trivial, insignificant, or unintelligent (Elitist Jerks, 2010a).

It is also possible to achieve celebrity status in the WoW community through a variety of means, some of which may be serendipitous. For example, a short video shared on the Internet in 2005 featuring a character named "Leeroy Jenkins" went viral due to its humorous critique of difficult in-game content. This resulted in mass community recognition of the player, as well as the character being the answer to a question on the television game show Jeopardy! ("Leeroy Jenkins," 2010). For those seeking personal fame in the community, achieving an enhanced reputation through knowledge contributions may be perceived as a means through which this status may be gained.

Social exchange theory posits that sharing knowledge may be motivated by creating an obligation on others in the community to reciprocate the exchange, leading to personal reward 
(Cyr \& Choo, 2010; Yang \& Farn, 2009). For example, through knowledge provided by others in the WoW community, one may learn what is required to obtain an in-game benefit, in the form of finding a difficult to obtain item, or perhaps by gaining an understanding of quicker and more efficient methods of earning in-game currency. Knowledge contribution has been mentioned above as critical to progression through end-game content. While this progression takes place as part of a group, one may be motivated to participate for the personal desire to experience this content or earn exclusive rewards that can only be gained through cooperation. Cyr and Choo further point out the personal benefits of heightened self-esteem, self-efficacy, and the enjoyment that may be associated with aiding others. Additional personal benefits may be meeting people, making friends, and building relationships (Chiu et al., 2006).

\section{Conclusion}

Returning to Nonaka and Takeuchi's (1995) understanding of knowledge production and the knowledge sharing framework identified by Hersberger et al. (2007), we are able to see that in online communities, these processes are made possible through the social bonds between members and the values of community participants. As discussed in this paper, in the case of the WoW community, players engage in both knowledge production and sharing through a diverse range of online networks, including wikis, web forums, and databases. In doing so, they share their personal experiences or play style preferences, collaborate to establish social norms (such as the aforementioned loot distribution system of Dragon Kill Points), exchange information through the asking and answering of questions, participate in the database creation by installing add-ons, and help players progress through game content by creating strategy guides or analyzing game mechanics. In all of these activities, we may see not only tacit and explicit knowledge being shared, but explicit knowledge produced through interaction and collaboration. As this community is a voluntary association, the motivations for participation in these out-of-game knowledge undertakings may be either community-focused or driven by the prospect of personal gains. Whatever the motivation behind the sharing behaviour, these member relationships are the vehicles through which knowledge production and exchange occurs. Looking at the WoW community itself as an example of knowledge sharing and production may have benefit to educational and business communities who seek to encourage students and employees to voluntarily share their expertise and contribute to the development of their peers. 


\section{References}

Achievement. (2010). In Wowwiki. Retrieved from http://www.wowwiki.com/Achievement

Ardichvili, A. (2008). Learning and knowledge sharing in virtual communities of practice: Motivators, barriers, and enablers. Advances in Developing Human Resources, 10(4), 541-554. doi: 10.1177/1523422308319536 $\underline{\text { rossRef }}$

Blizzard Entertainment. (2010a, October 07). World of Warcraft subscriber base reaches 12 million worldwide. Retrieved from http://us.blizzard.com/en-us/company/press/pressreleases.html?101007

Blizzard Entertainment. (2010b). World of Warcraft. Retrieved from http://us.battle.net/wow/en/

Bates. M. J. (2005). Information and knowledge: An evolutionary framework for information science. Information Research, 10(4), paper 239. Retrieved from http://InformationR.net/ir/10-4/paper239.html

Chen, M. (2008). Communication, coordination, and camaraderie in World of Warcraft. Games and Culture, 4(1), 47-73. doi: 10.1177/1555412008325478 CrossRef

Chu, K.-M. (2009). A study of members' helping behaviours in online community. Internet Research, 19(3), 279-292. doi: 10.1108/10662240910965351 CrossRef

Chiu, C. M., Hsu, M. H., \& Wang, E. T. G. (2006). Understanding knowledge sharing in virtual communities: An integration of social capital and social cognitive theories. Decision Support Systems, 42(3), 1872-1888. doi:10.1016/j.dss.2006.04.001 CrossRef

Choo, C. W. (1998). The management of learning—organizations as knowledge-creating enterprises. In The Knowing organization. How organizations use information to construct meaning, create knowledge, and make decisions. (pp. 105-153). New York: Oxford University Press, 1998.

Cyr, S., \& Choo, C.W. (2010). The individual and social dynamics of knowledge sharing - an exploratory study. Journal of Documentation, 66(6). CrossRef

Dragon Kill Points. (2010). In Wowwiki. Retrieved from http://www.wowwiki.com/DKP

Elitist Jerks. (2010a). Forum Rules. Retrieved from http://elitistjerks.com/misc.php?do=cfrules

Elitist Jerks. (2010b). Forums. Retrieved from http://elitistjerks.com/forums.php

Fitch, D. (2007). Wherefore Wikis? Journal of Technology in Human Services, 25(4), 79-85. doi:10.1300/J017v25n04_05 CrossRef 
Golub, A. (2010). Being in the World (Of Warcraft): Raiding, realism, and knowledge production in a massively multiplayer online game. Anthropological Quarterly, 83(1), 1745. $\underline{\text { CrossRef }}$

Hersberger, J. A., Murray, A. L., \& Rioux, K.S. (2007). Examining information exchange and virtual communities: An emergent framework. Online Information Review, 31(2), 135147. doi:10.1108/14684520710747194 CrossRef

Leeroy Jenkins. (2010). In Wowwiki. Retrieved from http://www.wowwiki.com/Leeroy Jenkins (video)

Putzke, J., Fischbach, K., Schoder, D., \& Gloor, P. (2010). The evolution of interaction networks in massively multiplayer online games. Journal of the Association for Information Systems, 11(2), 69-94. doi: 1982224411

Raban, D. R., \& Rafaeli, S. (2007). Investigating ownership and the willingness to share information online. Computers in Human Behavior, 23(5), 2367. doi:10.1016/j.chb.2006.03.013 CrossRef

Shivel, G. (2010). World of Warcraft: The Murloc is the message. Symploke, 17, 1, 205-213. CrossRef

Statistics. (2010) In Wowwiki. Retrieved from http://www.wowwiki.com/Special:Statistics

Withers, C. (2010, December 07). World of Warcraft gets facelift in "Cataclysm". The Globe and Mail. Retrieved from http://www.theglobeandmail.com

Yang, S. C., \& Farn, C. K. (2009). Social capital, behavioural control, and tacit knowledge sharing-A multi-informant design. International Journal of Information Management, 29(3), 210-218. $\underline{\text { CrossRef }}$

World of Warcraft Terminology. (2010). In Wowwiki. Retrieved from http://www.wowwiki.com/Acronym

Wowhead. (2010). What is Wowhead? Retrieved from http://www.wowhead.com/aboutus

Wowwiki: About. (2010) In Wowwiki. Retrieved from http://www.wowwiki.com/WoWWiki:About 